Table 1. Univariable and multivariable conditional logistic regression analyses for the association between periodontitis defined by various definitions and the risk of palindromic rheumatism

\begin{tabular}{lcc}
\hline & $\begin{array}{c}\text { Univariable } \\
\text { OR }(95 \% \mathrm{Cl})\end{array}$ & $\begin{array}{c}\text { Multivariable } \\
\text { OR }(95 \% \mathrm{Cl})\end{array}$ \\
\hline Various periodontitis exposure definitions & & \\
Periodontitis (ICD9: 523.3-5) & $1.50(1.41-1.60)$ & $1.51(1.41-1.61)$ \\
Chronic periodontitis (ICD9: 523.4$)$ & $1.36(1.20-1.54)$ & $1.37(1.21-1.55)$ \\
Acute or chronic periodontitis (ICD9: 523.3-4) & $1.56(1.46-1.67)$ & $1.57(1.46-1.68)$ \\
Gingival and periodontal diseases (ICD9: 523) & $1.56(1.46-1.66)$ & $1.56(1.47-1.67)$ \\
\hline
\end{tabular}

greater in those who had shorter lag time between the last date of PD diagnosis and PR index date and those who had a higher number of visits for PD or greater cumulative cost of PD-related visits.

Conclusions: This study demonstrated a time- and dose-dependent association between PD exposure and PR risk.

References:

[1] Sanmarti R, Canete JD, Salvador G. Palindromic rheumatism and other relapsing arthritis. Best practice \& research. Clin Rheumatol 2004;18(5):647612.

[2] Chen $\mathrm{HH}$, Huang $\mathrm{N}$, Chen $\mathrm{YM}$, et al. Association between a history of periodontitis and the risk of rheumatoid arthritis: a nationwide, populationbased, case-control study. Annals Rheumatic Diseases 2013;72(7):1206-11.

Acknowledgements: The authors would like to thank the Biostatistics Task Force of Taichung Veterans General Hospital, Taichung, Taiwan, ROC for statistical support.

Disclosure of Interest: None declared

DOI: 10.1136/annrheumdis-2017-eular.4719

\section{FRI0692 ALLOPURINOL AND THE RISK OF VENTRICULAR ARRHYTHMIAS IN THE ELDERLY: A STUDY USING U.S. MEDICARE DATA}

\section{J. Singh, J. Cleveland. University of Alabama at Birmingham, Birmingham,}

United States

Background: Recent studies have shown that hyperuricemia and gout, a condition with hyperuricemia associated with joint inflammation and/or renal manifestations, are associated with a higher risk of coronary artery disease (CAD), acute cardiovascular events including myocardial infarction (MI) and stroke, and cardiovascular mortality. Emerging data suggest that gout and hyperuricemia may also be associated with cardiac arrhythmias such as atrial fibrillation

Objectives: To assess whether allopurinol use is associated with a reduction in the risk of ventricular arrhythmias (VA).

Methods: We used the $5 \%$ random sample of Medicare beneficiaries from 20062012 to examine new allopurinol use and the risk of incident VA. Multivariable Cox regression analyses were adjusted for demographics (age, race, gender), comorbidity, cardiac medications and conditions associated with VA. We calculated hazard ratios $(\mathrm{HR})$ and $95 \%$ confidence intervals $(\mathrm{Cl})$.

Results: Of the 28,755 episodes of new allopurinol use, 2,538 were associated with incident VA (8.8\%). Among patients with incident VA, $54 \%$ were male, $78 \%$ were White, and the mean Charlson-Romano comorbidity score was 4.8 . The crude incidence of VA per 1,000,000 person-days declined as the duration of allopurinol use increased: $1-180$ days, 151; 181 days-2 years, 105; and > 2 years, 85. In multivariable-adjusted analyses, compared to non-use, allopurinol use was associated with lower HR of VA of $0.82(95 \% \mathrm{Cl}, 0.76$ to 0.90$)$. Compared to allopurinol non-use, longer allopurinol use durations were significantly associated with lower multivariable-adjusted HR for VA: 1-180 days, $0.96(95 \% \mathrm{Cl}, 0.85$ to 1.08$)$; 181 days to 2 years, $0.76(95 \% \mathrm{Cl}, 0.68$ to 0.85$)$; and $>2$ years, $0.72(95 \% \mathrm{Cl}, 0.60$ to 0.87$)$. Multiple sensitivity analyses adjusting for cardiac conditions, anti-arrhythmic drugs and alternate definitions confirmed our findings with minimal/no attenuation of estimates.

Conclusions: Allopurinol use and use duration $>6$ months were independently associated with a lower risk of VA. Future studies need to assess the pathophysiology of this potential benefit.

Disclosure of Interest: J. Singh Grant/research support from: Takeda, Savient, Consultant for: from Savient, Takeda, Regeneron, Merz, Iroko, Bioiberica, Crealta and Allergan pharmaceuticals, WebMD, UBM LLC and the American College of Rheumatology, J. Cleveland: None declared

DOI: 10.1136/annrheumdis-2017-eular.6811

\section{FRI0693 SYNOVIAL CHANGES DETECTED BY ULTRASONOGRAPHY AND THEIR ASSOCIATION WITH OSTEOARTHRITIS-RELATED} KNEE PAIN: A 1-YEAR PROSPECTIVE COHORT STUDY

A. Sarmanova $^{1,2}$, M. Hall ${ }^{2,3}$, G.S. Fernandes ${ }^{1,4}$, A.M. Valdes ${ }^{1,2}$, D.A. Walsh ${ }^{1,2}$, M. Doherty ${ }^{1,2}$, W. Zhang ${ }^{1,2}$. ${ }^{1}$ Division of Rheumatology, Orthopaedics and Dermatology, The University of Nottingham; ${ }^{2}$ Pain Centre, Arthritis Research UK; ${ }^{3}$ School of Health Sciences, The University of Nottingham; ${ }^{4}$ Centre for Sports, Exercise and Osteoarthritis, Arthritis Research UK, Nottingham, United Kingdom

Background: Recently an important role for synovial pathology in the initiation and progression of knee osteoarthritis (OA) has been emphasised. Our previous cross-sectional study showed that synovial changes on US associated with knee pain (KP), but the association was confounded by radiographic severity [1] Objectives: To examine whether these synovial changes associate with KP changes over 1 year.

Methods: 220 participants with early KP (<3yrs duration) identified from the Knee Pain and Related Health in the Community (KPIC, $n=9514$ ) survey in Nottingham, UK formed the cohort for this study. All participants had bilateral US and radiographic examination at baseline, and US was repeated after 1 year. KP was defined as pain in or around the knee on most days for at least a month, and KP severity was measured using a numerical rating scale (NRS 0-10). Change in KP severity was defined according to a Patient Global Impression of Change. Synovial changes (effusion, hypertrophy and Power Doppler (PD) signal) were measured by two observers (inter-observer concordance correlation was 0.8 (0.6 to 0.9 ) for effusion and 0.7 (0.5 to 0.9 ) for synovial hypertrophy). Standardised radiographs (semi-flexed weight-bearing and flexed skyline views) were scored using the Nottingham Line Drawing Atlas (NLDA). Radiographic OA was defined as definite joint space narrowing (grade 2) plus definite osteophyte (grade 2) in any compartment. An absolute change in effusion/synovial thickness/pain scores was calculated by subtracting the baseline measure from the follow-up measure within individuals. A correlation analysis was used to examine the association between changes in pain and changes in US values. Potential baseline predictors for KP worsening were examined using multivariate logistic regression analysis. Results: Of 220 participants in this cohort, 165 (75\%) had US measurements at baseline and follow-up (mean age $61 \mathrm{yrs} ; 61 \%$ women; $24 \%$ ROA). The mean NRS score decreased from 4.44 to $3.01 \mathrm{~mm}$. The mean depth of the effusion and synovial hypertrophy changed from $4.01 \mathrm{~mm}$ to $5.37 \mathrm{~mm}$, and from 1.82 to 2.45 $\mathrm{mm}$, respectively. There was no correlation between changes in pain on NRS and changes in US-detected synovial change (Figure 1).

At 1 year follow-up, 58\% reported that their KP had improved from baseline, $16 \%$ reported worsening, and $27 \%$ reported no change in KP. After adjustment for age, gender and BMI baseline US features did not predict worsening pain, whereas $\mathrm{ROA}$ did $(\mathrm{OR}=4.0695 \% \mathrm{Cl} 1.55$ to 10.61 ).
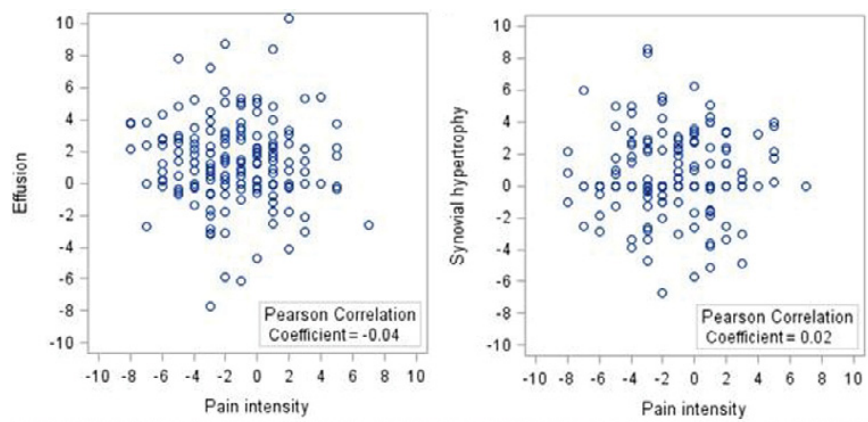

Figure 1. Corre

Conclusions: This cohort study showed that US-detected knee "synovitis" was not a predictor of change in OA symptoms, whereas baseline radiographic OA severity was. It suggests that synovial changes detected by US might reflect aspects of OA pathology discrete from mechanisms driving OA pain change. References:

[1] Sarmanova A, et al. Arthritis Rheumatol. 2016; 68 (suppl 10). http://acrabstracts.org/abstract/synovial-changes-detected-by-ultrasoundand-its-association-with-knee-pain-a-population-based-case-control-study/.

Acknowledgements: Arthritis Research UK (Grant Refs: 20777 and 20194) and Bolashak PhD Studentship.

Disclosure of Interest: None declared

DOI: 10.1136/annrheumdis-2017-eular.5764

\section{FRI0694 PREVALENCE OF RHEUMATIC DISEASE IN AN ADULT POPULATION FROM COLOMBIA. A COPCORD METHODOLOGY STUDY}

A.M. Santos ${ }^{1}$, J.C. Rueda ${ }^{1}$, J.-I. Angarita ${ }^{1}$, R. Giraldo ${ }^{1}$, E. Forero ${ }^{2}$

I. Pelaez-Ballestas ${ }^{3}$, J.G. Ballesteros Muñoz ${ }^{4}$, E.-L. Saldarriaga ${ }^{1}$, J. Ramirez ${ }^{5}$, C. Toro ${ }^{5}$, J. Londono ${ }^{6} .{ }^{1}$ Reumatología, Universidad de la Sabana, Chia:

${ }^{2}$ Medicina Interna, Reumatología, Universidad del Norte, Barranquilla, Colombia;

${ }^{3}$ Departamento de Reumatología, Hospital General de México, Ciudad de México, Mexico; ${ }^{4}$ Departamento de Medicina Interna, Hospital San José;

${ }^{5}$ Asociación Colombiana de Reumatología; ${ }^{6}$ Reumatología, Universidad de la Sabana-Hospital Militar Central, Bogotá, Colombia

Background: Rheumatic diseases are the leading cause of permanent disability. In our country are the fourth cause of consultation in health institutions. The COPCORD model constitutes an effective tool in the determination of the prevalence of diseases. Globally, this model has been carried out in Asia, Europe and in some countries of Latin America. In Colombia the epidemiology of rheumatic diseases is not known globally; this would be the first national study that uses the data collection questionnaire using the COPCORD instrument 
Objectives: To estimate the prevalence of rheumatic disease and related factors in a Colombian population over 18 years of age in six Colombian cities Methods: A Cross-sectional analytical study was designed in people older than 18 years. A probabilistic stratified sampling method using three stages. The first stage of sampling was the selection of cartographic sectors in each city. The second stage of sampling was the blocks of each sector. The third stage of sampling was the homes of each block. All household members were surveyed. The sample size was calculated to be 6,528 people (2336 from Bogotá, 1220 from Medellín and Cali each, 746 from Barranquilla, 503 from Bucaramanga and Cúcuta each). The COPCORD questionnaire adapted for Colombia, was applied in the first stage by standardized interviewers. Positive cases were reviewed at home by a first year rheumatology fellow. To assess whether it is a rheumatic disease; the positive cases for a probable rheumatic disease were reviewed by a second year rheumatology fellow and reviewed again with laboratory and image studies by a certified rheumatologist to establish the definitive diagnosis

Results: 3,146 men and 3,547 women were included. Pain in the last 7 days not associated with trauma was reported in 3,213 (48\%) participants. The most frequent sites were knees (right $31 \%$, left $29 \%$ ), hands (right $25 \%$, left $24 \%$ ), lumbar spine (18\%) and shoulders (right 16\%, left 14\%). Table 1 depicts the prevalence of rheumatic diseases in Colombia

Table 1. Prevalence of Rheumatic Disease in Colombia

\begin{tabular}{lccc}
\hline & Prevalence (\%) & Variation Coefficient & $\mathrm{Cl} 95 \%$ \\
\hline Osteoarthritis & 10,81 & 6 & $9,68-12,06$ \\
Gout & 0,56 & 26 & $0,33-0,92$ \\
Fibromyalgia & 0,72 & 22 & $0,47-1,11$ \\
Soft Tissue Rheumatism & 25,82 & 6 & $11,60-19,93$ \\
Mechanic Low Back Pain & 7,24 & 7 & $6,28-8,34$ \\
Inflammatory Low Back Pain & 0,65 & 28 & $0,38-1,12$ \\
Spondyloarthritis & 0,39 & 51 & $0,08-0,48$ \\
Rheumatoid Arthritis & 1,49 & 15 & $1,12-1,98$ \\
Systemic Lupus Erythematosus & 0,05 & 56 & $0,02-0,16$ \\
Sjögren Syndrome & 0,08 & 61 & $0,02-0,27$ \\
Dermatomyositis & 0,03 & 100 & $0,00-0,23$ \\
Scleroderma & 0,02 & 100 & $0,00-14$ \\
CHIKV infection & 6,68 & 8 & $5,73-7,78$ \\
\hline
\end{tabular}

$\mathrm{Cl}$ : confidence interval; CHIKV: chikungunya virus.

Conclusions: Our study shows a similar prevalence to those worldwide in scleroderma, dermatomyositis, systemic lupus erythematosus, and spondyloarthritis. A lower prevalence was observed in Sjögren Syndrome, fibromyalgia, gout and osteoarthritis. A slightly higher prevalence of rheumatoid arthritis was observed in our population. The high prevalence of rheumatoid arthritis and soft tissue rheumatism should increase awareness in our governmental health entities given their long term disability risk

Disclosure of Interest: None declared

DOI: 10.1136/annrheumdis-2017-eular.5646

\section{FRI0695 SERIOUS INFECTION ACROSS BIOLOGIC TREATED PATIENTS WITH RHEUMATOID ARTHRITIS: RESULTS FROM A NATIONAL REGISTRY}

A.I. Rutherford $^{1}$, S. Subesinghe ${ }^{1}$, R. Byng-Maddick ${ }^{2}$, K. Hyrich ${ }^{3}$,

J.B. Galloway ${ }^{1} .{ }^{1}$ Academic Rheumatology Department, King's College London;

${ }^{2}$ Rheumatology, Homerton Hospital, London; ${ }^{3}$ Arthritis Research UK Centre for

Epidemiology, University of Manchester, Manchester, United Kingdom

Background: Infection is a complication of biologic therapy in RA.

Objectives: To describe the incidence and pattern of serious infection within the British Society for Rheumatology Biologics Register (BSRBR-RA) by drug.

Methods: The BSRBR-RA is a prospective observational study designed to evaluate the safety of biologics. Adverse events are coded using MedDRA defintitions. This analysis included patients with RA starting a biologic. They were considered at risk from their start date until 3 half-lives after stopping their biologic, death, first serious infection, or completion of three years of therapy, whichever came first. Event rates were compared across biologics using Cox proportional hazards with adjustment for age, gender, disease severity and duration, smoking, seropositivity, polypharmacy and baseline steroid usage.
Results: 19,282 patients were included in the analysis with combined follow-up time of 46,771 years. At baseline the mean age was 57 years, $76 \%$ female, mean disease duration 12.3 years and mean DAS28 6.1. 22\% were current smokers and $64 \%$ had a positive rheumatoid factor. The incidence of serious infection for each biologic and hazard ratios for serious infections including by subclass are tabulated.

A sensitivity analysis limiting to 1st biologic exposure only did not significantly alter the estimates. A second sensitivity analysis limiting to new starters from 2010 found certolizumab still had a lower point estimate but findings were no longer significant (HR 0.79, $\mathrm{Cl}$ 0.54-1.16).

Conclusions: Although the incidence of serious infection was lowest with certolizumab it is difficult to draw strong conclusions about comparative safety from observational studies due to channelling bias and unmeasured confounding. Rituximab and tocilizumab both had higher unadjusted rates of infection but in the adjusted model the rate was no different suggesting that patient factors as opposed to the drug itself were responsible for the observed difference.

Disclosure of Interest: A. Rutherford: None declared, S. Subesinghe: None declared, R. Byng-Maddick: None declared, K. Hyrich Grant/research support from: Pfizer, Speakers bureau: Abbvie, J. Galloway Consultant for: Roche, BMS, UCB, Pfizer

DOI: 10.1136/annrheumdis-2017-eular.1711

\section{FRI0696 IMPACT OF ADALIMUMAB THERAPY ON BRACHIAL ENDOTHELIAL FUNCTION AND LARGE ARTERY STIFFNESS IN PATIENTS WITH RHEUMATOID ARTHRITIS}

A.L. Demoux ${ }^{1}$, K. Aissi ${ }^{1}$, B. Chaudier ${ }^{2}$, S. Carijn ${ }^{3}$, P.-Y. Chouc ${ }^{3}$, H. De Baillou ${ }^{3}$, P. Rossi ${ }^{1} .{ }^{1}$ Internal medicine department, public hospital of Marseille; ${ }^{2}$ Internal Medicine Deprtement, Laveran Hospital; ${ }^{3}$ CONCERTO Association, Marseille, France

Background: Anti-TNF alpha treatment may improve endothelial function and mechanical properties of large artery stiffness in patients with inflammatory rheumatic diseases, however studies remain controversial.

Objectives: To study the effect of TNF alpha blockage with adalimumab for 24 weeks on brachial endothelial function and sub-clinical markers of atherosclerosis in patients with inflammatory rheumatic diseases.

Methods: A total of 26 patients ( 14 males, 12 females; mean age, $47 \pm 11$ years) with inflammatory rheumatic diseases (16, rheumatoid arthritis; 9, ankylosing spondylitis, 1, psoriasic rheumatism), resistant to disease-modifying antirheumatic drugs, were studied before the first infusion of adalimumab and again after 24 weeks of treatment. Endothelial function was assessed by measuring flow mediated dilatation using an ultrasound Doppler technique on the brachial artery. Other markers of sub clinical atherosclerosis were assessed by arterial stiffness via aortic pulse wave velocity, augmentation index and central blood pressure, and carotid intima-media thickness. Data for body mass index, disease activity using DAS-PCR and BASDAI, C-reactive protein, fasting glycaemia, and lipid profile were collected before treatment and after 24 weeks.

Results: 24 weeks of adalimumab therapy resulted in a reduction of disease activity score and serum levels of C-reactive protein. No significant differences were found in body mass index, total cholesterol, triglycerides and fasting glycaemia. Brachial blood pressure and heart rate remained similar, as well as carotid intima-media thickness. After 24 weeks of treatment with adalimumab, flow mediated dilatation improved significantly; central systolic and diastolic blood pressure decreased significantly; however central pulse pressure, augmentation index and aortic pulse wave velocity remained unchanged.

Conclusions: In patients with inflammatory rheumatic diseases, treatment with adalimumab for 24 weeks resulted in a significant improvement of endothelial function and central arterial pressure.

Disclosure of Interest: A. L. Demoux Grant/research support from: Abbvie, K. aissi: None declared, B. chaudier: None declared, S. carijn: None declared, P.-Y. chouc: None declared, H. de baillou: None declared, P. rossi: None declared DOI: 10.1136/annrheumdis-2017-eular.6128

\begin{tabular}{|c|c|c|c|c|c|c|}
\hline & Etanercept & Infliximab & Adalimumab & Rituximab & Tocilizumab & Certolizumab \\
\hline \multicolumn{7}{|l|}{ Primary Analysis } \\
\hline Follow-up (yrs) & 15314 & 8829 & 13071 & 5910 & 1963 & 1685 \\
\hline Infections (single failure) & 852 & 472 & 709 & 372 & 137 & 64 \\
\hline Incidence per 100 patient years $(95 \% \mathrm{Cl})$ & $5.56(5.20,5.95)$ & $5.35(4.89,5.85)$ & $5.42(5.04,5.84)$ & $6.29(5.69,6.97)$ & $6.98(5.90,8.25)$ & $3.80(2.97,4.85)$ \\
\hline Serious Infection Hazard Ratio $(95 \% \mathrm{Cl})$ & Ref & $0.94(0.84,1.06)$ & $0.97(0.88,1.07)$ & $1.15(1.01,1.30)$ & $1.22(1.02,1.47)$ & $0.65(0.51,0.84)$ \\
\hline Adjusted HR $(95 \% \mathrm{Cl})$ & Ref & $0.87(0.77,1.00)$ & $0.98(0.88,1.08)$ & $0.91(0.80,1.04)$ & $1.17(0.93,1.47)$ & $0.69(0.52,0.92)$ \\
\hline \multicolumn{7}{|c|}{ Adjusted Hazard Ratio By Infection Class (95\% Cl) } \\
\hline Sepsis/Bacteraemia & Ref & $0.83(0.41,1.66)$ & $1.04(0.57,1.91)$ & $2.08(1.14,3.80)$ & $1.83(0.63,5.35)$ & $1.03(0.24,4.41)$ \\
\hline Respiratory Infection & Ref & $1.16(0.96,1.39)$ & $1.23(1.04,1.45)$ & $1.03(0.83,1.28)$ & $1.61(1.15,2.25)$ & $0.96(0.63,1.46)$ \\
\hline Skin Infection & Ref & $0.84(0.66,1.06)$ & $0.65(0.52,0.82)$ & $0.54(0.39,0.75)$ & $0.71(0.40,1.24)$ & $0.27(0.11,0.67)$ \\
\hline Gastrointestinal Infection & Ref & $0.95(0.66,1.38)$ & $0.77(0.54,1.11)$ & $0.93(0.61,1.42)$ & $1.45(0.72,2.90)$ & $0.51(0.16,1.63)$ \\
\hline Bone/Joint Infection & Ref & $0.56(0.38,0.83)$ & $0.80(0.58,1.09)$ & $0.67(0.43,1.02)$ & $0.46(0.17,1.27)$ & $0.73(0.32,1.68)$ \\
\hline Genitourinary Infection & Ref & $0.74(0.50,1.07)$ & $1.18(0.87,1.59)$ & $1.15(0.79,1.68)$ & $0.67(0.27,1.66)$ & $0.55(0.20,1.52)$ \\
\hline Other & Ref & $0.54(0.31,0.91)$ & $1.08(0.74,1.58)$ & $0.72(0.41,1.29)$ & $1.15(0.49,2.67)$ & $0.50(0.16,1.60)$ \\
\hline
\end{tabular}

